\title{
MENINGKATKAN KEMAMPUAN PEMAHAMAN KONSEP MATEMATIK SISWA SMP DENGAN PENDEKATAN KONTEKSTUAL
}

\author{
Muhamad Yadin ${ }^{1}$, Euis Eti Rohaeti ${ }^{2}$, Luvy Sylviana Zanthy ${ }^{3}$ \\ 1,2,3 IKIP Siliwangi, Jalan Terusan Jenderal Sudirman Cimahi, Cimahi Tengah, Kota Cimahi \\ 1Mochyadin75@gmail.com²e2rht@ikipsiliwangi.ac.id,3luvy.zanthy@ikipsiliwangi.ac.id
}

\begin{abstract}
This investigate is motivated by the low ability to comprehend the mathematical concepts of SMP students in KBB, so a learning approach is needed to decipher these problems. Alternative approaches are applied, namely the contextual approach. The method make use of in this investigate is an experimental method with a control group design pretest posttest. The population in this research were all junior high schools in KBB while the school sample was Kahuripan Lembang Middle School which was chosen based on school randomization. Sample class were taken randomly from the 4 classes of class 7 of Kahuripan Lembang Middle School, class 7-2 as the tentative class and class 7-4 as the control class. The tentative class uses contextual learning while the ordinary learning control class. The reason for taking class VII is because with deliberation in the semester one there are topics in the Triangle and Quadrangle that will be used in the study. The instrument in this investigation was a package of five test questions. The researcher can conclude that the achievement and repair of the capability of understanding The mathematical concept of SMP students who use a contextual approach is better than those using ordinary learning.
\end{abstract}

Keyword: Ability to Understand Concepts, Contextual Approach.

\begin{abstract}
Abstrak
Penelitian ini didasari oleh rendahnya kemampuan yaitu pemahaman konsep matematik siswa yang ada di SMP di KBB, sehingga diperlukan penggunaan pendekatan pembelajaran untuk menyelesaikan permasalahan tersebut. Opsi pendekatan yang dipakai adalah kontekstual. Sedangkan metode yang dipakai dalam kegiatan riset ini adalah eksperimen dengan desainnya adalah kelompok kontrol dengan pretes dan postes. Populasi yang digunakan didalam penelitian ini ialah seluruh SMP di KBB sedangkan sampel sekolahnya adalah SMP Kahuripan Lembang yang dipilih berdasarkan acak sekolah. Sampel kelas diambil dengan cara acak terhadap 4 kelas dari kelas 7 di SMP Kahuripan Lembang dan diperoleh kelas VII-2 yang diputuskannya menjadi kelas eksperimen sedangkan kelas VII-4 diputuskan menjadi kelas kontrol. Model pembelajaran yang diputuskan di kelas percobaan ialah pembelajaran kontekstual melainkan di kelas acuan ialah pembelajaran konvensional. Alasan diambilnya kelas VII karena dengan pertimbangan pada semester satu terdapat materi ajar Segitiga dan Segi Empat yang nantinya akan dipakai saat penelitian. Alat penelitian yang dipergunakan ialah 5 buah soal dengan bentuknya uraian. Yang dapat disimpulkan oleh peneliti ialah adanya pencapaian dan peningkatan dari kemampuan pemahaman konsep matematik pada siswa SMP yang pembelajaran dikelasnya diterapkan pendekatan kontekstual hasilnya lebih bagus dari yang pembelajaran dikelasnya diterapkan pembelajaran konvensional.
\end{abstract}

Kata Kunci: Kemampuan Pemahaman Konsep, Pendekatan Kontekstual

How to cite: Yadin, M., Rohaeti, E. E., Zanthy, L. S. (2019). Meningkatkan Kemampuan Pemahaman Konsep Matematik Siswa SMP dengan Pendekatan Kontekstual. JPMI - Jurnal Pembelajaran Matematika Inovatif, 2 (5), 337-344. 


\section{PENDAHULUAN}

Manusia hidup pada hakikatnya amat memerlukan pendidikan. Zaman sekarang ini, penyeragaman dan keprofesionalan dalam pendidikan menuntut adanya pemahaman bagi dari berbagai macam orang terhadap adanya berbagai modifikasi yang terjadi di setiap bagian dari sebuah sistemnya pendidikan itu sendiri. Menurut Gita, Dantes, \& Sariyasa (2014), Matematika adalah pengetahuan dasar yang memiliki fungsi penting dalam hampir setiap aspek kehidupan manusia. Matematika menjadi disiplin ilmu yang wajib diajarkan mulai dari Sekolah Dasar (SD) sampai dengan jenjang Sekolah Menengah Atas (SMA). Sejalan dengan Mawaddah \& Maryanti (2016), SMP merupakan jenjang pendidikan dasar yang mempunyai tujuan agar supaya meletakkan dasar kepintaran, pengetahuan, sikap, akhlak baik, serta keterampilan untuk hidup berdiri sendiri dan berpartisipasi untuk pendidikan lebih lanjut.

Menurut Hardini dan Puspitasari (Gita et al., 2014), Perkembangan pesat yang terdapat dan terjadi di lingkup teknologi informasi serta komunikasi pada saat ini didasarkan oleh adanya perubahan ke arah lebih baik matematika di bidang teori bilangan yaitu aljabar, menganalisis, teori peluang dan juga matematika diskrit yang dimanfaatkan penggunaanya dalam rangka menguasai dan menciptakan kemajuan teknologi di masa depan itu jelas-jelas dibutuhkan kemampuan menguasai matematika yang kukuh sejak kecil. Berdasarkan anggapan mengenai hal di atas, dapat diambil benang merahnya yakni berkembangnya Ilmu Pengetahuan dan Teknologi (IPTEK) dilandasi oleh matematika.

Menurut Afrilianto (2016), Proses pembelajaran itu sejatinya adalah bentuk interaksi edukatif, yakni interaksi yang bernilai pendidikan dan dengan sadar menaruh tujuan untuk merubah perilaku dan perbuatan seseorang. Wardhani (Mawaddah \& Maryanti, 2016), Pada dasarnya pembelajaran matematika itu ialah sebuah kegiatan mempelajari suatu hal yang dibangun oleh guru untuk mengembangkan kreativitas berpikir siswa dan bisa memiliki keahlian mengkonstruks pengetahuan baru agar yang melakukan pembelajaran matematika itu memiliki penguasaan yang meningkat terhadap materi matematika.

Selain itu, umumnya ketika pembelajaran matematika aktivitas siswa kurang dioptimalkan. Hal ini sama seperti hasil studi dari Sumarmo (Afrilianto, 2012) yang dilakukan pada siswa SMA, SMP, dan guru di Kodya Bandung dimana hasilnya adalah kurang dilibatkannya pekerjaan siswa secara maksimal dalam aktivitas suatu belajar dan pembelajaran matematika dimana dampaknya ialah siswa kurang memberikan respon ketika proses belajar mengajar. Tak sejalan dengan Mulyasa (Heris, Rohaeti, \& Sumarmo, 2014), pembelajaran diharuskan banyak melibatkan aktivitas siswa, supaya siswa itu bisa mengeksplorasikan sesuatu sehingga mampu membentuk kompetensi melalui penggalian kemampaun yang terdapat pada diri dan kebenaran itu kedalam bentuk lain yang ilmiah. Hal itu sejalan dengan pendapat Heris et al (2014), dalam paradigma baru, proses pembelajaran tidak lagi berpusat pada guru (teacher-centered), tetapi bergeser menjadi berpusatkan kepada si siswa (student-centered).

Di dasarkan hasil konsultasi interviu peneliti di lapangan dengan guru yang mengajar matematika di SMP Kahuripan Lembang, pemahaman konsep pada matematik pada siswa kiranya jauh dari harapan. Hal ini didapat dari lapangan yang menunjukkan tingkat aneksasi pada siswa pada materi pelajaran matematika yang masih rendah. Beberapa faktor yang mengakibatkan hal tersebut diantaranya adalah siswa itu sendiri, fasilitas proses pembelajaran yang masih kurang siap serta strategi dan kegiatan proses pembelajaran yang telah diberikan oleh guru itu di kelas masih monoton. 
Sejalan dengan penelitian Mawaddah \& Maryanti (2016), Meskipun telah disebutkan bahwasannya tujuan pembelajaran materi matematika di SMP adalah agar siswa mempunyai kemampuan pemahaman pada konsep, tetapi kenyataannya Di dasarkan hasil konsultasi interviu dengan guru yang mengajar matematika dan siswa-siswa di SMP hasilnya diketahui bahwa kemampuan siswa akan pembelajaran matematika itu masih rendah, seiring dengan itu diketahui pula bahwa masih ada siswa yang belum paham mengenai pelajaran yang diberi oleh guru, serta matematika cenderung masih dianggap materi ajar yang susah dan pada akhirnya matematika itu tidak disukai oleh siswa. Hal tersebut diatas berdampak pada nilai rata-rata siswa yang berada dibawah KKM yaitu sebesar 65 pada UTS.

Departemen Pendidikan Nasional (2007) (Gita et al., 2014), Menyatakan ada beberapa aspek yang baik untuk dikembangkan pada pembelajaran matematika, diantaranya ialah pemahaman konsep, pemecahan masalah dan penalaran juga komunikasi. Pemahaman konsep ialah acuan yang sangat penting, karena nantinya jika penguasaan konsep siswa baik dapat merangsang siswa akan mudah mengikuti pembelajaran matematika.

Kemampuan pemahaman konsep di utarakan oleh Asikin (Hartati, Abdullah, \& Haji, 2017) adalah kemampuan memahami sesuatu untuk mengerti kemudian merubah informasi yang didapat ke dalam bentuk dan model yang lain yang lebih memiliki makna tersendiri. Kemampuan pemahaman konsep itu juga merupakan kemampuan yang ekstensif dan juga fungsional dalam memahami ide-ide matematika. Menurut Kilpatrick, Swafford, \& Findell (Hartati et al., 2017), pemahaman konsep (conceptual understanding) ialah keahlian dalam mengerti lebih mendalam konsep, operasi juga hubungan di dalam matematika.

Dalam usaha menjadikan lebih baik kemampuan pemahaman konsep siswa, pembelajaran diharuskan menggunakan model yang pas juga disesuaikan dengan kebutuhan anak. Pendekatan kontekstual itu ialah pendekatan yang berusaha menyatukan proses pembelajaran dengan kondisi siswa, jadinya siswa mampu dengan mudah memahami konteks yang sedang siswa pelajari. Untuk menguatkan pemahaman konsep bagi siswa SMP, guru dapat mengaitkan dengan situasi yang dialami siswa. Salah satu alternatif siasat yang dapat diambil adalah dengan digunakannya benda nyata yang sering ditemukan siswa dalam kehidupan sehari-hari sebagai media untuk menjelaskan materi.

Dengan begitu bisa disimpulkan bahwa pemahaman konsep pada matematik pada siswa SMP itu masih dibawah rata-rata, oleh karena hal itu diharuskan diadakan penelitian dalam upaya untuk memberikan peningkatan akan pemahaman konsep pada matematik dengan diterapkannya pendekatan proses belajar pembelajaran yang cocok. Satu diantaranya pendekatan yang bisa diterapkan adalah pendekatan Contekstual Teaching and Learning (CTL) atau pendekatan kontekstual. Menurut Hartati et al (2017), Model pembelajaran kontekstual merupakan sesuatu model pembelajaran dimana model ini mengharuskan siswa terlibat disetiap tahapan pembelajaran. Menurut Sanjaya (Bernard, 2016), model pembelajaran kontekstual itu nyatanya mengaitkan tujuh bagian utama pembelajaran, yakni kontruktivisme, bertanya, menemukan, masyarakat yang belajar, pemodelan, bayangan dan penilaian sebenarnya.

\section{METODE}

Metode yang diterapkan dalam kegiatan riset ini ialah metode eksperimen. Metode merupakan prosedur dalam penelitian yang dipakai untuk memperoleh hubungan sebab dan akibat dua buah variabel ataupun lebih dengan cara dikendalikannya pengaruh faktor yang lain. Penelitian ini diadakan agar bisa ditinjau ada atau tidak sesuatu perubahan meningkatnya kemampuan pemahaman pada konsep matematik untuk siswa yang diberikan pembelajarannya dengan 
pendekatan Contekstual Teaching and Learning (CTL) dengan siswa yang diterapkannya pembelajaran biasa. Pada tahap awal dan tahap akhir pembelajaran kedua kelas itu diberikan tes sehingga desain penelitiannya menurut Ruseffendi (2010), adalah sebagai berikut:
A $\mathrm{O}$
$\mathrm{X} \quad \mathrm{O}$
A $\quad \mathrm{O}$
$\mathrm{O}$

Keterangan:

A : Pengambilan sampel secara acak berdasarkan kelas.

O : Tes awal (pretest) $=$ tes akhir (postest).

X : Pembelajaran dengan pendekatan Contekstual Teaching and Learning (CTL)

Teknik pengumpulan data yang digunakan dalam penelitian ini berupa tes (pretes dan postes) dan N-gain. Tes digunakan untuk mengetahui kemampuan pemahaman konsep matematika siswa terhadap pembelajaran matematika pada materi segi empat menggunakan pembelajarannya Contekstual Teaching and Learning (CTL). analisis data dari hasil penelitian, yaitu data pretes dan postes. Pengolahan data kuantitatif dilakukan dengan menggunakan software khusus pengolahan data, software yang digunakan adalah software spss 16 untuk pengujian hipotesis statistik.

Untuk analisis pencapaian kemampuan pemahaman konsep digunakan skor postes dengan Uji Mann-Whitney. Didapat bahwa pencapaian kemampuan pemahaman konsep matematik siswa SMP yang menggunakan pendekatan kontekstual lebih baik daripada yang menggunakan pembelajaran konvensional. Sedangkan untuk peningkatan kemampuan pemahaman konsep menggunakan skor gain ternormalisasi dengan perhitungan gain ternormalisasi dari Hake (Aripin, 2015), sebagai berikut :

$$
\mathrm{g}=\frac{\text { skor tes akhir-skor tes awal }}{\text { skor maksimum ideal-skor tes awal }}
$$

Tingkat perolehan skor gain ternormalisasi dikelompokkan kedalam tiga kategori, yaitu :

$\begin{array}{ll}0,70<(\mathrm{g}) & \text { : Tinggi } \\ 0,30 \leq(\mathrm{g}) \leq 0,70 & \text { : Sedang } \\ (\mathrm{g})<0,30 & \text { : Rendah }\end{array}$

Pengolahan skor gain ternormalisasi menggunakan uji perbedaan dua rata-rata. Menghasilkan kesimpulan bahwa peningkatan kemampuan pemahaman konsep matematik siswa SMP yang menggunakan pendekatan kontekstual lebih baik daripada yang menggunakan pembelajaran konvensional.

\section{HASIL DAN PEMBAHASAN}

\section{Hasil}

Berdasarkan hasil dari penelitian dan analisis dari data terhadap sampel penelitian, tujuannya adalah agar diketahui bahwa kemampuan pemahaman konsep pada matematik siswa yang kegiatan belajar dan pembelajarannya itu diterapkan pendekatan kontekstual itu lebih bagus dari yang diterapkannya pembelajaran yang konvensional.

Statistik yang didapatkan dari riset ini ialah skor hasil pretes dan juga skor hasil postes. Skor pretes dijadikan patokan dalam rangka mengetahui kemampuan pemahaman konsep pada matematik pada siswa sebelum pemberian tindakan, sedangkan skor postes dijadikan patokan dalam rangka mengetahui kemampuan pemahaman konsep pada matematik pada siswa setelah diberi tindakan dan untuk melihat pencapaian, peningkatan, implementasi pendekatan 
kontekstual, dan kesulitan yang didapat siswa ketika menyelesaikan soal kemampuan pemahaman konsep matematik antara yang memperoleh tindakan melalui pendekatan kontekstual itu lebih bagus daripada siswa yang mendapatkan tindakan dengan pembelajaran konvensional.

Untuk lebih memudahkan saat menganalisis data skor hasil pretes juga skor postes, berikut disajikan deskripsi statistik hasil skor hasil pretes juga postes kemampuan pemahaman konsep pada matematik siswa yang adanya di kelas eksperimen juga kelas kontrol. Dapat terlihat pada bentuk Tabel 1 berikut:

Tabel 1. Deskripsi Statistik Hasil Skor Kemampuan Pemahaman Konsep Matematik

\begin{tabular}{lccccccccc}
\hline \multirow{2}{*}{ Data } & \multicolumn{3}{c}{ Pretes } & \multicolumn{4}{c}{ Postes } & \multicolumn{3}{c}{ Gain } \\
\cline { 2 - 10 } & $\mathbf{N}$ & $\overline{\boldsymbol{x}}$ & $\mathbf{S}$ & $\mathbf{N}$ & $\overline{\boldsymbol{x}}$ & $\mathbf{S}$ & $\mathbf{N}$ & $\overline{\boldsymbol{x}}$ & $\mathbf{S}$ \\
\hline Kelas Eksperimen & 36 & 4,72 & 1,68 & 36 & 15,81 & 1,92 & 36 & 0,72 & 0,12 \\
Kelas Kontrol & 36 & 4,61 & 1,73 & 36 & 12,56 & 2,17 & 36 & 0,55 & 0,13 \\
\hline SMI
\end{tabular}

SMI adalah 20

Berdasarkan Tabel 1, rerata pretes kelas eksperimen dan pretes kelas kontrol yaitu 4,72 dan 4,61 artinya secara deskriptif tidak terdapat perbedaan secara signifikan antar kelas eksperimen dengan kontrol. Rerata postes kelas eksperimen dan postes kelas kontrol yaitu 15,81 dan 12,56 artinya secara deskriptif pencapaian kemampuan pemahaman konsep matematik siswa SMP yang menggunakan pendekatan kontekstual lebih baik daripada yang menggunakan pembelajaran konvensional. Sedangkan Rerata gain kelas eksperimen dan gain kelas kontrol yaitu 0,72 dan 0,55 artinya secara deskriptif peningkatan kemampuan pemahaman konsep matematik siswa SMP yang menggunakan pendekatan kontekstual lebih baik daripada yang menggunakan pembelajaran konvensional. Selanjutnya untuk mendukung deskripsi kemampuan pemahaman matematik yang telah dijelaskan, maka dilakukan analisis data kemampuan pemahaman konsep matematik siswa SMP melalui uji statistik dengan menggunakan bantuan software spss 16 dan disajikan dalam Tabel 2, Tabel 3, Tabel 4, didapat hasil sebagai berikut:

Tabel 2. Rekapitulasi Pengujian Perbedaan Rerata Data Pretes Kemampuan Pemahaman Konsep Matematik

\begin{tabular}{clccc}
\hline & Kelas & $\mathrm{N}$ & Signifikan & Keterangan \\
\hline \multirow{2}{*}{ Pretes } & $\begin{array}{l}\text { Eksperimen } \\
\text { Kontrol }\end{array}$ & 36 & 0,783 & $\mathrm{H}_{\mathrm{O}}$ diterima \\
\hline
\end{tabular}

Berdasarkan Tabel 2. nilai signifikanya yaitu 0,783. Jika dengan taraf kesalahan dari uji hipotesis dua pihak 5\%, maka 0,783>0,05. Karena (Sig) untuk kedua kelas lebih besar dari 0,05 maka berdasarkan kriteria pengujiannya di atas maka $\mathrm{H}_{\mathrm{O}}$ diterima. Dapat disimpulkan bahwa kemampuan awal pemahaman konsep matematik siswa SMP yang menggunakan pendekatan kontekstual tidak berbeda secara signifikan daripada yang menggunakan pembelajaran konvensional.

Tabel 3.Rekapitulasi Pengujian Mann-Whitney Data Postes Kemampuan Pemahaman Konsep Matematik

Skor Postes

\begin{tabular}{lc} 
Mann-Whitney U & 439.000 \\
Asymp. Sig. (2-tailed) & 0.017 \\
\hline
\end{tabular}


Berdasarkan Tabel 4.6, dapat dilihat bahwa nilai signifikannya yaitu $0,017 \leq 0,05$. Dapat disimpulkan bahwa pencapaian kemampuan pemahaman konsep matematik siswa SMP yang menggunakan pendekatan kontekstual lebih baik daripada yang menggunakan pembelajaran konvensional.

Tabel 4. Rekapitulasi Pengujian Perbedaan Rerata Data Gain Kemampuan Pemahaman Konsep Matematik

\begin{tabular}{clccc}
\hline & Kelas & $\mathrm{N}$ & Signifikan & Keterangan \\
\hline \multirow{2}{*}{ Pretes } & $\begin{array}{l}\text { Eksperimen } \\
\text { Kontrol }\end{array}$ & 36 & 0,013 & Ho ditolak \\
\hline
\end{tabular}

Berdasarkan Tabel 4. dapat dilihat nilai signifikannya yaitu $0,013 \leq 0,05$, maka $\mathrm{H}_{O}$ ditolak. Dapat disimpulkan bahwa peningkatan kemampuan pemahaman konsep matematik siswa SMP yang menggunakan pendekatan kontekstual lebih baik daripada yang menggunakan pembelajaran konvensional.

\section{Pembahasan}

Didasarkan pada hasil analisis skor pretes diantara kelasnya eksperimen serta kelas kontrol yang sudah dilakukan, sehingga terlihat tidak adanya perbedaan kemampuan awal pemahaman suatu konsep pada matematik siswa. Lain dari hal itu, hasil tersebut menunjukan dimana kemampuan pemahaman suatu konsep pada matematik bagi siswa belum memuaskan. Faktor yang menjadi penyebab hal itu satu diantaranya ialah kurang terbiasanya siswa ketika proses pembelajaran. Seperti siswa itu masih belum biasa dalam menyelesaikan soal yang diberikan oleh peneliti, dan juga kegiatan pembelajaran yang mengharuskan siswa itu untuk berupaya aktif serta kreatif ketika kegiatan dan suatu proses belajar pembelajaran di kelas.

Kegiatan awal pembelajaran diawali dengan dibentuknya suatu kelompok yang anggotanya enam orang yang heterogen. Setiap kelompok mengerjakan LKS berupa masalah yang tidak langsung ditemukan penyelesaiannya dan masalah yang ada kaitan eratnya dengan permasalahan nyata. Ketika diskusi, siswa mengamati masalah dan menyelesaikannya sesuai dengan yang tertera di LKS, siswa diberikan kebebasan untuk mencari penyelesaian sesuai pengetahuan yang telah sebelumnya mereka miliki, dan guru menjadi fasilitator. Dikarenakan hal itu, cara penyelesaian setiap kelompok pasti berbeda. Hal ini sejalan dengan penelitian yang dilakukan oleh Bernard (2016).

Dalam kegiatan riset ini, peneliti memberikan motivasi kepada siswa agar aktif dan kreatif dalam pembelajaran tersebut, baik dengan langkah memberi masukan maupun sanggahan, tetapi tidak setiap siswa bisa seperti pas dengan apa saja yang sudah diharapkan. Setelah proses pembelajaran secara berkelompok selesai, selanjutnya peneliti merefleksi siswa dengan mempersilakan satu kelompok untuk mempresentasikan pekerjan mereka didepan kelas. Ketika kelompok tersebut mempresentasikan prediksi jawaban kepada teman-temannya maka kelompok lain yang membuat pertanyaan menanggapinya. Jika ada pertanyaan ataupun pemberian soal yang masih tidak bisa diselesaikan, guru mengevaluasi bersama siswa dan mengklarifikasi tentang jawaban-jawaban yang telah diprediksi oleh kelompok lain.

Rintangan-rintangan yang dialami peneliti ketika kegiatan belajar pembelajaran yang dilaksanakan pada kelas eksperimen, ialah siswa tidak terbiasa dengan pendekatan yang diterapkan oleh peneliti yaitu pendekatan kontekstual. Karena mereka telah terbiasa dengan 
kegiatan belajar pembelajaran yang konvensional. Lemahnya kemampuan dasar siswa sehingga menyulitkan kegiatan belajar mengajar. Hal ini nampak dari adanya sebagian siswa yang belum mampu menunjukkan keaktifannya ketika kegiatan pembelajaran berlangsung. Selain itu, waktu pembelajaran yang singkat untuk pembelajaran melalui pendekatan kontekstual menjadi kesukaran yang ditemukan saat proses pembelajaran (Simbolon \& Tapilouw, 2016). Namun, peneliti berusaha untuk mengoptimalkan waktu yang ada dengan mempersingkat kegiatan awal pembelajaran dan ketika presentasi.

Selanjutnya yang ada di kelas kontrol itu pembelajarannya dengan diterapkannya pembelajaran konvensional. Dalam kelas kontrol tidak diberikan masalah-masalah serta musyawarah kelompok sepenuhnya yang menyerupai kelas eksperimen. Pada pembelajaran konvensional, proses pembelajarannya dipusatkan pada guru, agar interaktif diantara si guru dengan siswa kurang terjalin karena tidak menghasilkan suatu proses timbal balik diantara guru dengan siswa. Ruseffendi (2006) Mengatakan, Pada metode ini yang banyak bicara adalah pembicara. Interaksi yang terjadi hanya antara penceramah dan pendengar. Komunikasi biasanya itu hanya satu arah, yaitu dari pembicara ke pendengar. Kesulitan yang dihadapi di kelas kontrol, tidak ada bedanya secara substansial dengan yang terdapat di kelas eksperimen. Dalam kelas kontrol siswa kebanyakan agak lebih pasif dikarenakan siswa hanya memerhatikan apa yang dijelaskan oleh peneliti.

Setelah dilakukannya kegiatan pembelajaran dimana kelas eksperimen mendapat pembelajaran yang menggunakan pendekatan kontekstual sedangkan yang kelas kontrol menerapkan pembelajaran konvensional untuk sepuluh kali pertemuan. Peneliti mengadakan postes dipertemuan selanjutnya, tujuannya agar diketahui secara pasti apakah adanya perbedaan yang pasti bagi kelas eksperimen dengan kelas kontrol.

Terdapat beberapa penyebab yang menyebabkan adanya perbedaan yang pasti antara kelas eksperimen dengan kelas kontrol, salah satunya karena terdapat perbedaan pada langkahlangkah pembelajaran diantara pendekatan kontekstual dengan pembelajaran konvensional. Hal ini membuktikan bahwasannya kegiatan belajar pembelajaran yang memakai pendekatan kontekstual itu lebih bagus dari yang proses pembelajarannya yang menerapkan pembelajaran konvensional.

\section{KESIMPULAN}

Pencapaian kemampuan pemahaman konsep pada matematik siswa SMP yang pembelajarannya menggunakan pendekatan kontekstual lebih baik daripada yang pembelajarannya menggunakan pembelajaran konvensional. Peningkatan kemampuan pemahaman konsep pada matematik siswa SMP yang pembelajarannya menggunakan pendekatan kontekstual lebih baik daripada yang pembelajarannya menggunakan pembelajaran konvensional.

\section{UCAPAN TERIMA KASIH}

Penulis mengucapkan terimakasih kepada Dr. Hj. Euis Eti Rohaeti, M.Pd. dan Luvy Sylviana Zanthy, M.Pd. karena dukungan dan bimbingannya dalam menyelesaikan penelitian ini. Sehingga penelitian ini selesai sampai di publikasikan. 


\section{DAFTAR PUSTAKA}

Afrilianto, M. (2012). Peningkatan Pemahaman Konsep dan Kompetensi Strategis Matematis Siswa SMP dengan Pendekatan Metaphorical Thinking. Infinity Journal, 1(2), 192-202.

Afrilianto, M. (2016). Peningkatan Pemahaman Konsep dan Kompetensi Strategis Matematis Siswa SMP dengan Pendekatan Metaphorical Thinking. Infinity Journal. https://doi.org/10.22460/infinity.v1i2.19

Aripin, U. (2015). Meningkatkan Kemampuan Pemahaman Matematik Siswa SMP melalui Pendekatan Pembelajaran Berbasis Masalah. P2M STKIP Siliwangi. https://doi.org/10.22460/p2m.v2i1p120-127.171

Bernard, M. (2016). Meningkatkan Kemampuan Komunikasi Dan Penalaran Serta Disposisi Matematik Siswa Smk Dengan Pendekatan Kontekstual Melalui Game Adobe Flash Cs 4.0. Infinity Journal, 4(2), 197. https://doi.org/10.22460/infinity.v4i2.84

Gita, P., Dantes, N., \& Sariyasa. (2014). Pengaruh Model Reciprocal Teaching Terhadap Pemahaman Konsep dan Motivasi Belajar Matematika Siswa kelas V SD. E-Journal Program Pascsarjana Universitas Pendidikan Ganesha, 4, 1-10.

Hartati, S., Abdullah, I., \& Haji, S. (2017). Pengaruh Kemampuan Pemahaman Konsep, Kemampuan Komunikasi dan Koneksi Terhadap Kemampuan Pemecahan Masalah. MUST: Journal of Mathematics Education, Science and Technology, 2(1), 43-72. https://doi.org/10.30651/must.v2i1.403

Heris, H., Rohaeti, E. E., \& Sumarmo, U. (2014). Hard Skills dan Soft Skills Matematik Siswa. Infinity Journal, 1, 56.

Mawaddah, S., \& Maryanti, R. (2016). Kemampuan Pemahaman Konsep Matematis Siswa SMP dalam Pembelajaran Menggunakan Model Penemuan Terbimbing (Discovery Learning). Jurnal Pendidikan Matematika, 4(1), 76-85.

Ruseffendi, E. T. (2006). Pengantar kepada Membantu Guru Mengembangkan Kompetensinya dalam Pengajaran Matematika untuk Meningkatkan CBSA (Tarsito). Bandung.

Ruseffendi, E. T. (2010). Dasar-Dasar Penelitian Pendidikan dan Bidang Non Eksakta Lainnya. Bandung: Tarsito.

Simbolon, E. R., \& Tapilouw, F. S. (2016). Pengaruh Pembelajaran Berbasis Masalah Dan Pembelajaran Kontekstual Terhadap Berpikir Kritis Siswa Smp. Edusains, 7(1), 97-104. https://doi.org/10.15408/es.v7i1.1533 